\title{
BMJ Open Associations between objectively assessed and questionnaire-based sedentary behaviour with BMI-defined obesity among general population children and adolescents living in England
}

\author{
Ngaire A Coombs, ${ }^{1,2,3,4}$ Emmanuel Stamatakis ${ }^{1,2,5,6,7}$
}

To cite: Coombs NA, Stamatakis E. Associations between objectively assessed and questionnaire-based sedentary behaviour with BMI-defined obesity among general population children and adolescents living in England. BMJ Open 2015;5:e007172. doi:10.1136/bmjopen-2014007172

- Prepublication history for this paper is available online. To view these files please visit the journal online (http://dx.doi.org/10.1136/ bmjopen-2014-007172).

Received 11 November 2014 Revised 24 February 2015 Accepted 20 March 2015

CrossMark

For numbered affiliations see end of article.

Correspondence to Dr Ngaire Coombs; n.coombs@soton.ac.uk

\section{ABSTRACT}

Objectives: Sedentary behaviour (SB) is an emerging candidate risk factor for obesity in young people. Evidence to date is conflicting and it is unclear how different SB types are associated with obesity independently of physical activity. The objective of this study was to examine associations between a range of objectively measured and questionnaire-based SB indicators with obesity and body mass index (BMI) to assess whether these associations were independent of physical activity.

Participants: 4469 (705 with accelerometer data) children aged 5-15 years from the 2008 Health Survey for England.

Outcomes: The outcome was adiposity, classified using age-specific and sex-specific BMI SD scores (continuous) and obesity cut-offs (binary).

Questionnaire-based measures comprised TV time, non-TV sitting time (such as homework, drawing, time at a computer or playing video games), total sitting time (TV time+non-TV sitting time) and average daily MVPA time. Objective SB and moderate to vigorous physical activity (MVPA) time were measured using an Actigraph GT1M accelerometer, with cut-offs of 100 and 200 counts per minute for SB, and 2802 counts per minute for MVPA. Multiple logistic and multiple linear regression models examined associations between each indicator of sedentary time with obesity and BMI SD scores.

Results: TV time (but not non-TV sitting or objectivelymeasured SB) was consistently associated with higher levels of obesity and BMI SD score, even after adjusting for MVPA and other potential confounders. Weaker associations were observed for total sitting time.

Conclusions: TV viewing (but not other forms of objectively-measured or questionnaire-based sedentary time) was associated with obesity in children and adolescents. Although a causal relationship cannot be established, TV time may be a reasonable target for obesity prevention in young populations.

\section{Strengths and limitations of this study}

- This study uses a large, nationally representative sample and multiple indicators of objectively assessed and questionnaire-based sedentary time.

- The cross-sectional study design precludes causal inferences about the association between TV time and childhood obesity.

- A limitation of objectively measured sedentary time is that it does not differentiate between lying, sitting and standing, which have different health implications.

\section{INTRODUCTION}

Physical activity in youth is associated with better adiposity profiles ${ }^{12}$ and a higher likelihood of being active as an adult. ${ }^{3}$ Sedentary behaviour (SB), characterised by low-energyexpenditure activities $(<1.5$ metabolic equivalents) in a sitting or reclining posture, such as watching television (TV) or sitting in the classroom, ${ }^{4}$ is an emerging risk factor for cardiometabolic disease later in $\operatorname{life}^{5-7}$ and has attracted considerable attention as a candidate risk marker in young people. ${ }^{8-11} \mathrm{SB}$ is very pervasive among youth in Western countries. The average daily accelerometry estimated SB of those aged 5-15 years in England is $7-8 \mathrm{~h}$; over $45 \%$ of boys and $47 \%$ of girls in England spend more than $2 \mathrm{~h}$ a day watching TV on weekdays. ${ }^{12}$ Current public health guidelines in several countries, including the UK, ${ }^{13}$ the $\mathrm{USA}^{14}$ and Canada, ${ }^{15}$ recommend a minimum of 60 min of moderateto-vigorous physical activity (MVPA) a day for school-age children and adolescents, although the corresponding recommendations for total daily SB are more generic and 
not as specifically quantified. This may be due to the relatively undeveloped evidence base, as SB has attracted substantial research attention in the last 5-6 years only. Specific quantitative recommendations for reductions of TV time (usually $<2 \mathrm{~h} /$ day) are in place in several countries, including Canada, ${ }^{15}$ Australia ${ }^{16}$ and the USA. ${ }^{17}$

Prolonged SB in youth has attracted attention as a potential risk factor for obesity, although the evidence is far from conclusive. Studies that measure SB objectively using accelerometers generally find no association, ${ }^{18-20}$ although TV viewing consistently shows direct associations with adiposity-related outcomes. ${ }^{8} 2122$ We have recently reported differential associations between indicators of screen time and multiple indices of adiposity in a population sample of 17509 Portuguese children where TV time, but not computer or video gaming time, was consistently associated with the outcomes. ${ }^{23}$ It is not clear whether the lack of association reported in the accelerometry studies is due to properties of the measuring instrument (such as accelerometers classifying standing as $\mathrm{SB}$ ), or if it simply signifies that as long as young people engage in MVPA, prolonged SB does not influence obesity risk. Using both objective and questionnairebased SB measurement methods may provide a more complete account of the true associations of SB with obesity. To the best of our knowledge, no studies of SB and adiposity in young people have compared objective measures with questionnaire-based measures of total SB.

The aim of this study was to examine associations between SB (defined using objective and questionnairebased methods) and obesity in a large general population sample of children and adolescents aged 5-15 years living in England.

\section{METHODS}

\section{Sample}

The Health Survey for England (HSE) is a nationally representative survey of individuals living in private households in England, conducted annually. The 2008 HSE included a boost sample of children aged 2-15 years and focused on physical activity and SB. Data were collected using questionnaire-based and (for a randomly selected subsample) accelerometry. A multistage stratified sample design was used, and addresses were randomly selected within specified postcode sectors. Up to two children were randomly selected in each household. 5587 children aged 5-15 years took part in the 2008 HSE. Of these, 1516 children were included in the boost sample and asked to wear an accelerometer for 7 days, with 779 $(54 \%)$ providing valid accelerometer data for at least 1 day $(10 \mathrm{~h})$ and the vast majority of these providing valid accelerometry data for 3 days (48\%). ${ }^{24} 25$ Of the children selected for accelerometry who did not provide data, around $15 \%$ refused to wear the accelerometer, around $2 \%$ were ineligible and a fault rendered over $20 \%$ of the data unusable (in a non-systematic manner), with the rest missing due to incomplete wear time. ${ }^{24}$ Informed consent was obtained from the parents or guardians of the children who served as participants, and from the children themselves. More details of the sample design are available elsewhere. ${ }^{26}$ The household-response rate was $64 \%$ for the main sample and $73 \%$ for the accelerometer subsample.

\section{Measurements}

Questionnaire-based sedentary time and physical activity

Questionnaire-based SB was assessed by a parental proxy interview-administered questionnaire for children aged 5-12 years, and by interview for participants aged 1315 years. Children (or their parents) were asked to report the average number of minutes spent watching TV or DVDs/videos, and non-TV sitting time per weekday and weekend day, outside of school time. Examples given for non-TV sitting time included homework, drawing, time at a computer or playing video games. Information was also collected on average weekday and weekend day MVPA time, including the frequency (number of days in the past 4 weeks) and duration (minutes per day) of participation in walking for any purpose and recreational exercise (eg, cycling, swimming, aerobics, dancing or racket sports).

\section{Objective sedentary time and physical activity}

The accelerometer used was the Actigraph GT1M (ActiGraph, Pensacola, USA), a uniaxial accelerometer that captures vertical movement. Participants were requested to wear the accelerometer on a belt around the waist during waking hours for seven consecutive days, apart from when showering or swimming. Some participants also removed the accelerometer when engaged in contact sports. Non-wear time was defined as $60 \mathrm{~min}$ or more of consecutive zero counts. A 1 min epoch was used. For objectively measured sedentary time, two different cut-points were used (less than $100^{18}$ and less than 200 counts $^{20}$ per minute (CPM) , and for MVPA the cutpoint was 2802 or more CPM. ${ }^{26}{ }^{27}$ Data were analysed using custom analysis software (Kinesoft, V.3.3.19).

\section{Adiposity}

Height $(\mathrm{cm})$ and weight $(\mathrm{kg})$ were measured by trained interviewers using standard protocols that have been described in detail elsewhere. ${ }^{12}$ Body mass index (BMI) was calculated by dividing weight $(\mathrm{kg})$ by height $(\mathrm{m})$ squared. While BMI is an anthropometric measure and not a direct measure of adiposity (such as dual X-ray absorptiometry or percentage body fat), it has long been acknowledged as a valid indicator of adiposity in children. ${ }^{28}$ Additionally, direct measurement of adiposity is often expensive, time-consuming and/or requires specialised equipment and highly trained technicians, which is impractical for a large population-based survey. BMI values were converted to age-specific and sex-specific SD scores (SDS), and additionally converted to an agespecific and sex-specific obesity indicator using established methodology. ${ }^{29} 29$ Briefly, the egen function in Stata 
was used to convert BMI values into age-specific and sexspecific SDS based on the 1990 British Growth Reference population-based reference data. Respondents were also allocated to obese or not obese categories using agespecific and sex-specific BMI cut-offs recommended by the Childhood Obesity Working Group of the International Obesity Taskforce. ${ }^{29}$

\section{Demographic and contextual variables}

Information on participant age (years), sex, fruit and vegetable consumption (portions per day), and head of household social class (managerial, technical and professional, skilled non-manual, skilled manual, semi-skilled manual, unskilled manual) were also collected by the survey interviewers.

\section{Data handling}

The highest two social class categories (managerial, and technical and professional) were collapsed into one category due to the absence of any obese participants in the managerial category. Questionnaire-based total sitting time was computed by summing TV time and non-TV sitting time. For questionnaire-based sedentary time and MVPA variables, average daily values were calculated using the following formula: ((weekday time $\times 5)$ $+($ weekend day time $\times 2)) / 7$. All continuous variables except age and accelerometer wear time were reduced to \pm 3 SDs of the mean to improve normality, excluding between $2.2 \%$ and $6.4 \%$ of cases, depending on the exposure. The final sample size was 705 for objectively measured sedentary time and 4469 for questionnairebased sedentary time.

\section{Statistical analyses}

The associations between each of the sedentary time exposures and BMI outcomes were examined using multiple logistic regression for the binary obesity indicator, and multiple linear regression for continuous BMI SDS. We tested for interactions between age group and sex, and each of the sedentary time exposures. As none of these interaction terms were significant, we did not stratify by age or sex. Age, sex, fruit and vegetable consumption, and social class were included as covariates in the analyses, although they were consistently insignificant in all models, due to their importance as key demographic, dietary and socioeconomic predictors of obesity in children. Area deprivation and household income were also considered as covariates, but were also consistently insignificant in all models, and in the case of household income had a high proportion of missing values. Household-level social class was considered a more superior indicator of socioeconomic status than arealevel deprivation, and as such area deprivation and household income were not included in the analyses.

Model 1 was adjusted for age, sex and accelerometer wear time (for accelerometry exposures). Model 2 was additionally adjusted for head of household occupational social class and portions of fruit and vegetables per day. Model 3 was also adjusted for objectively measured or questionnaire-based MVPA, as appropriate. Non-response weights and survey design were taken into account using the complex samples module in SPSS. Residuals from multiple linear regression models were checked for normality, independence, homoscedasticity and linearity.

\section{RESULTS}

\section{Descriptives}

Obese participants were more likely to be living in households where the head of the household was in a manual occupation, spent more time watching TV and less time in MVPA (as measured by accelerometry) than participants who were not obese (table 1). On average, obese participants spent $17 \mathrm{~min}$ more per day watching TV than non-obese participants $(p<0.001)$, and also spent more time sitting overall, but did not spend more time in non-TV sitting.

\section{SB and obesity}

Objectively measured sedentary time (100 and 200 CPM cut-offs) was not associated with obesity in any of the models (table 2). TV time and total sitting time per day were positively associated with obesity in all models $(\mathrm{p}<0.001)$, but non-TV leisure time sitting was not. After adjusting for all covariates, including questionnairebased MVPA, every $1 \mathrm{~h}$ increase in daily TV time was associated with a $42 \%$ increase in the risk of obesity (OR $1.42,1.20$ to 1.68$)$.

\section{SB and BMI}

We found similar results when the associations between SB and adiposity were examined using multiple linear regression and BMI SDS as an outcome (table 3): objectively measured sedentary time and non-TV leisure time sitting were not associated with BMI, while TV time and total sitting time were positively associated with BMI in every model $(p<0.001$ for TV time, $p=0.004$ for total sitting time). Every $1 \mathrm{~h}$ increase in daily TV time was associated with an increase in BMI SDS of 0.13 (0.07 to $0.18)$ SDs.

\section{DISCUSSION}

This study examined the associations between objectively measured and questionnaire-based SB and BMI-measured adiposity in a large population sample of children and adolescents. TV time, but not other measures of SB, was directly associated with adiposity, with a $1 \mathrm{~h}$ /day increase in $\mathrm{TV}$ viewing associated with an increase in the risk of obesity of $42 \%$. Total questionnaire-based sitting time was associated with adiposity, but this was driven by TV time: no association was found for the other component, non-TV leisure time sitting. Other studies have also found positive associations between TV and other screen time and adiposity in children who were independent of any intensity physical activity. ${ }^{923}$ Objectively measured SB was 
Table 1 Sample characteristics of selected variables by obesity* status

\begin{tabular}{|c|c|c|c|c|c|c|c|c|}
\hline & & \multicolumn{2}{|c|}{ Not obese } & & \multicolumn{2}{|l|}{ Obese } & \multirow[b]{2}{*}{ OR† } & \multirow[b]{2}{*}{ p Value $\ddagger$} \\
\hline & & $\begin{array}{l}\text { Per } \\
\text { cent }\end{array}$ & $\mathbf{N}$ & & $\begin{array}{l}\text { Per } \\
\text { cent }\end{array}$ & $\mathbf{N}$ & & \\
\hline \multicolumn{9}{|l|}{ Categorical variables } \\
\hline Sex $(\%$ male $)$ & & 49.6 & 4183 & & 50.7 & 286 & 1.04 & 0.720 \\
\hline \multirow{2}{*}{$\begin{array}{l}\text { Head of household occupational social class } \\
\text { (\% manual) }\end{array}$} & & 39.7 & 4183 & & 49.0 & 286 & 1.46 & 0.002 \\
\hline & Median & IQR & $\mathbf{N}$ & Median & IQR & $\mathbf{N}$ & r† & p Valueł \\
\hline \multicolumn{9}{|l|}{ Continuous variables } \\
\hline Age (years) & 10.5 & (5.4) & 4183 & 10.4 & (4.6) & 286 & -0.01 & 0.699 \\
\hline Portions of fruit and vegetable per day & 3.0 & (2.7) & 4183 & 3.0 & (3.3) & 286 & 0.00 & 0.807 \\
\hline TV viewing (min/day) & 102.9 & $(81.4)$ & 4183 & 120.0 & (102.9) & 286 & -0.09 & $<0.001$ \\
\hline Non-TV leisure time sitting (min/day) & 98.6 & $(77.1)$ & 4183 & 99.3 & $(77.1)$ & 286 & 0.00 & 0.766 \\
\hline Total leisure time sitting ( $\mathrm{min} /$ day) & 210.0 & (128.6) & 4183 & 225.0 & (157.1) & 286 & -0.05 & 0.001 \\
\hline Self-reported MVPA (min/day) & 40.7 & $(64.3)$ & 4183 & 33.1 & $(60.4)$ & 286 & -0.02 & 0.234 \\
\hline $\begin{array}{l}\text { Objectively measured sedentary time (100CPM) } \\
\text { (min/day) }\end{array}$ & 372.4 & $(145.2)$ & 670 & 403.3 & (162.5) & 35 & -0.03 & 0.467 \\
\hline $\begin{array}{l}\text { Objectively measured sedentary time (200CPM) } \\
\text { (min/day) }\end{array}$ & 438.8 & $(144.6)$ & 670 & 458.2 & $(151.4)$ & 35 & -0.03 & 0.451 \\
\hline Objectively measured MVPA time (min/day) & 58.5 & (54.8) & 670 & 42.7 & (34.6) & 35 & -0.09 & 0.022 \\
\hline Accelerometer wear time per valid day (min) & 759.5 & $(85.9)$ & 670 & 770.8 & $(122.5)$ & 35 & -0.01 & 0.755 \\
\hline \multicolumn{9}{|c|}{$\begin{array}{l}\text { *Obesity status was classified using age-specific and sex-specific BMI cut-offs recommended by the Childhood Obesity Working Group of the } \\
\text { International Obesity Taskforce. } \\
\text { †Effect size estimated by OR for categorical, and by } r \text { (calculated as } Z / \sqrt{ } N \text { ) from Mann-Whitney } U \text { test for continuous variables. } \\
\text { fp Value was calculated by } \chi^{2} \text { for categorical variables, and by Mann-Whitney } U \text { test for continuous variables. } \\
\text { BMI, body mass index; CPM, counts per minute; MVPA, moderate to vigorous physical activity. }\end{array}$} \\
\hline
\end{tabular}

not associated with adiposity, which has also been reported previously. ${ }^{81830}$

The lack of association between non-TV sitting and the adiposity outcomes may be due to the differential measurement error. Both parental proxy reporting and questionnaire-based young people's SB are prone to recall bias and TV time may be easier to recall accurately than other types of leisure time sitting, given that it often takes place in a central, visible location in the house (living room), and is delineated into memorable 'blocks' of time (TV programmes). In contrast, non-TV leisure time sitting comprises 'everything else' and is subject to higher measurement error. However, if recall bias was the reason that a significant association with adiposity was seen for TV viewing but not other questionnaire-based sitting, one would expect to find a

Table 2 Logistic regression ORs and $95 \%$ Cls describing the associations ${ }^{*}$ between sedentary time and obesity status

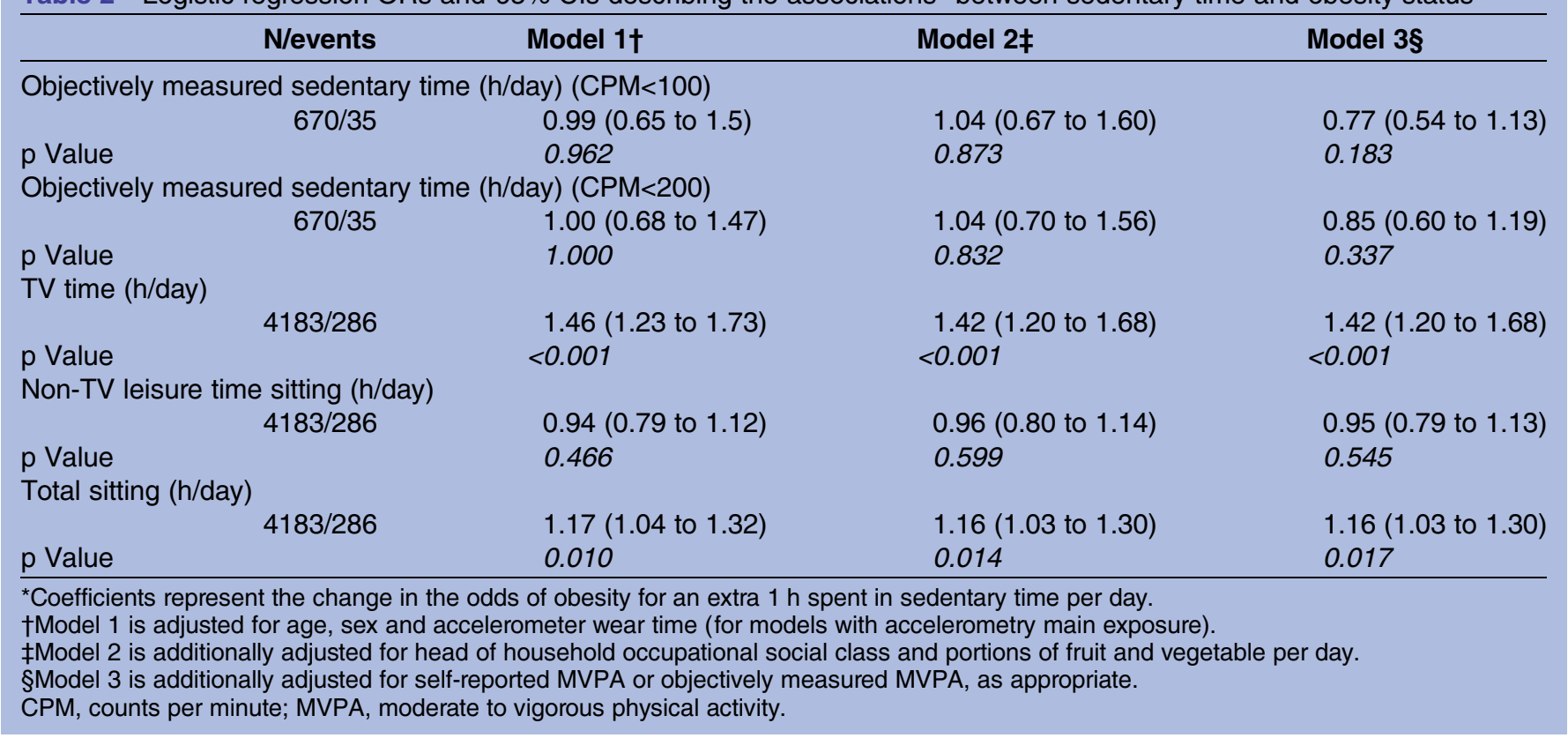


Table 3 Linear regression $\beta$ coefficents and $95 \%$ Cls describing the associations ${ }^{*}$ between sedentary time and BMI SDs

\begin{tabular}{|c|c|c|c|}
\hline $\mathbf{N}$ & Model 1† & Model 2ł & Model $3 \S$ \\
\hline \multicolumn{4}{|c|}{ Objectively measured sedentary time (h/day) $(C P M<100)$} \\
\hline 705 & $0.02(-0.08$ to 0.12$)$ & $0.02(-0.09$ to 0.12$)$ & $-0.02(-0.04$ to 0.00$)$ \\
\hline $\mathrm{p}$ Value & 0.696 & 0.749 & 0.056 \\
\hline \multicolumn{4}{|c|}{ Objectively measured sedentary time ( $h /$ day) $(C P M<200)$} \\
\hline 705 & $0.01(-0.08$ to 0.11$)$ & $0.01(-0.09$ to 0.11$)$ & $-0.09(-0.20$ to 0.01$)$ \\
\hline $\begin{array}{l}p \text { Value } \\
\text { TV time (h/dav) }\end{array}$ & 0.818 & 0.877 & 0.087 \\
\hline 4465 & 0.12 (0.07 to 0.18$)$ & 0.12 (0.07 to 0.18$)$ & 0.13 (0.07 to 0.18$)$ \\
\hline \multicolumn{3}{|c|}{ Non-TV leisure time sitting (h/day) } & $<0.001$ \\
\hline 4465 & $-0.01(-0.07$ to 0.05$)$ & $-0.01(-0.06$ to 0.05$)$ & $0.00(-0.06$ to 0.05$)$ \\
\hline \multicolumn{4}{|l|}{ Total sitting (h/day) } \\
\hline 4465 & 0.05 (0.02 to 0.09$)$ & 0.05 (0.02 to 0.09$)$ & 0.06 (0.02 to 0.09$)$ \\
\hline $\mathrm{p}$ Value & 0.005 & 0.006 & 0.004 \\
\hline
\end{tabular}

${ }^{*}$ Coefficients represent the change in BMI SD score for an extra $1 \mathrm{~h}$ spent in sedentary time per day.

†Model 1 is adjusted for age, sex and accelerometer wear time (for models with accelerometry main exposure).

†Model 2 is additionally adjusted for head of household occupational social class and portions of fruit and vegetable per day.

$\S$ Model 3 is additionally adjusted for self-reported MVPA or objectively measured MVPA, as appropriate.

$\mathrm{BMI}$, body mass index; CPM, counts per minute; MVPA, moderate to vigorous physical activity.

significant association for objectively measured SB, which is not affected by recall bias.

An alternative hypothesis is that children are more likely to snack on high-calorie food and drink when watching TV than when engaged in other forms of leisure time sitting, such as using a computer, playing video games or doing homework. A recent review found that screen time and TV viewing were associated with poor diet in children and adolescents, ${ }^{31}$ and a study of Greek children found that the association between TV viewing time and obesity became insignificant when total energy intake was accounted for. ${ }^{32}$ Another review found that screen time (predominantly TV viewing) was associated with increased dietary intake even in the absence of food advertising. ${ }^{33}$ The authors suggest that this may be due to distraction (not noticing how much is being consumed, or feelings of fullness); TV viewing acting as a cue to eat energy-dense foods (resulting from habit); and impairment of memory formation (not vividly or accurately remembering how much food was eaten while watching TV, resulting in higher subsequent consumption). ${ }^{33}$ However, most of these mechanisms can be equally applied to other forms of leisure time sitting, such as using a computer, playing video games or doing homework, which we did not find to be significantly associated with obesity. A possible explanation is that watching TV is passive and does not require any active input from the child, whereas the other forms of sitting described require the child to concentrate and use a keyboard, hold a controller or a pen, inhibiting the ability to concurrently eat or drink. Having to pause and stop typing or put down the controller/pen in order to consume food may also reduce the likelihood of distraction and impairment of memory formation leading to overeating. A recent study found a stronger association between TV time and consumption of sugary drinks than for total screen time, ${ }^{34}$ supporting the hypothesis that higher food consumption occurs during TV viewing than other forms of leisure time sitting.

In addition to increased food consumption during TV viewing, TV viewing may also indirectly increase children's energy consumption through exposure to food and drink adverts shown between children's TV programmes, ${ }^{35}$ with between $4 \%$ and $18 \%$ of childhood obesity in Britain thought to be attributable to TV food advertising. ${ }^{36}$ Other forms of leisure time sitting are not subject to such exposure to food advertising.

The strengths of this study include the large, nationally representative sample, and the use of multiple indicators of objectively assessed and questionnaire-based sedentary time. The limitations include the cross-sectional design, which precludes causal inferences about the association between TV time and obesity in children. In particular, we cannot rule out the possibility of bidirectional causality, that is, obese children are more likely to watch more TV. However, other studies have found TV time to be prospectively associated with adiposity in children. ${ }^{37}$ Another limitation is the inability of SB measured by an accelerometer to differentiate between sitting and standing, which have different health implications. It has been argued that standing should not be considered a SB, ${ }^{38}$ although the use of accelerometers to identify time spent sedentary is widespread. However, time spent standing still may be minimal, especially in young children. The sample had a broad age range, from 5 to 15 years, with sedentary time reported by parental proxy at younger ages. If the association between SB and obesity changes over childhood, or if parental proxy and self-reported estimates of sedentary time are markedly different, failing to stratify by age would produce invalid results; however, we found no evidence of interactions between broad age group and SB in predicting obesity. 


\section{CONCLUSION}

TV time, but not other measures of sedentary time, was associated with BMI-measured adiposity and obesity in children, after adjusting for MVPA. While a causal relationship cannot be established from this study, interventions to reduce obesity in childhood and adolescence may benefit from a focus on reducing TV time.

\section{Author affiliations}

${ }^{1}$ Department of Epidemiology and Public Health, University College London, London, UK

${ }^{2}$ PARG (Physical Activity Research Group), Population Health Domain, University College London, London, UK

${ }^{3}$ Department of Social Statistics and Demography, University of Southampton, Southampton, UK

${ }^{4}$ Department of Primary Care and Population Sciences, University of Southampton, Southampton, UK

${ }^{5}$ Prevention Research Collaboration, School of Public Health, University of Sydney, Sydney, Australia

${ }^{6}$ Charles Perkins Centre, University of Sydney, Sydney, Australia

${ }^{7}$ Department of Exercise Science Discipline, Faculty of Health Sciences, University of Sydney, Sydney, Australia

Acknowledgements This work was funded by the National Institute for Health Research through a Career Development Fellowship (ES). NC was also funded by the National Institute for Health Research through the same source.

Contributors NC and ES conceived the idea. NC conducted the analyses; ES and NC interpreted the results, wrote parts of the manuscript and revised it. Both the authors were involved in the writing of the manuscript and had final approval of the submitted and published versions.

Funding This research received no specific grant from any funding agency in the public, commercial or not-for-profit sectors.

Disclaimer The views expressed in this article are those of the authors and not the English Department of Health or the National Institute for Health Research.

Competing interests None declared.

Ethics approval Ethical approval was obtained from the Oxford Research Ethics Committee (reference number 07/H0604/102).

Provenance and peer review Not commissioned; externally peer reviewed.

Data sharing statement No additional data are available.

Open Access This is an Open Access article distributed in accordance with the Creative Commons Attribution Non Commercial (CC BY-NC 4.0) license, which permits others to distribute, remix, adapt, build upon this work noncommercially, and license their derivative works on different terms, provided the original work is properly cited and the use is non-commercial. See: http:// creativecommons.org/licenses/by-nc/4.0/

\section{REFERENCES}

1. Steele RM, van Sluijs EM, Cassidy A, et al. Targeting sedentary time or moderate and vigorous-intensity activity: independent relations with adiposity in a population-based sample of 10 -y-old British children. Am J Clin Nutr 2009:90:1185-92.

2. Ness AR, Leary SD, Mattocks C, et al. Objectively measured physical activity and fat mass in a large cohort of children. PLoS Med 2007;4:476-84.

3. Telama R, Yang X, Viikari J, et al. Physical activity from childhood to adulthood: a 21-year tracking study. Am J Prev Med 2005;28:267-73.

4. Tremblay M. Standardized use of the terms sedentary and sedentary behaviours. Appl Physiol Nutr Metab 2012;37:540-2.

5. Chomistek AK, Manson JE, Stefanick ML, et al. Relationship of sedentary behavior and physical activity to incident cardiovascular diseaseresults from the women's health initiative. J Am Coll Cardiol 2013:61:2346-54.
6. Wijndaele $\mathrm{K}$, Brage $\mathrm{S}$, Besson $\mathrm{H}$, et al. Television viewing and incident cardiovascular disease: prospective associations and mediation analysis in the EPIC norfolk study. PLOS ONE 2011;6: e20058.

7. Stamatakis E, Hamer M, Dunstan DW. Screen-based entertainment time, all-cause mortality, and cardiovascular eventspopulation-based study with ongoing mortality and hospital events follow-up. J Am Coll Cardiol 2011;57:292-9.

8. Ekelund U, Brage S, Froberg K, et al. TV viewing and physical activity are independently associated with metabolic risk in children: the European youth heart study. PLoS Med 2006;3:e488.

9. Lioret S, Maire B, Volatier JL, et al. Child overweight in France and its relationship with physical activity, sedentary behaviour and socioeconomic status. Eur J Clin Nutr 2007;61:509-16.

10. Must A, Tybor DJ. Physical activity and sedentary behavior: a review of longitudinal studies of weight and adiposity in youth. Int $J$ Obes 2005;29:S84-96.

11. Crespo CJ, Smit E, Troiano RP, et al. Television watching, energy intake, and obesity in US children. Arch Pediatr Adolesc Med 2001;155:360-5.

12. Joint Health Surveys Unit. The health survey for England 2008 : physical activity and fitness. Leeds: The Information Centre for Health and Social Care, 2010.

13. Department of Health. Physical activity, health improvement and protection. Start active, stay active: a report on physical activity for health from the four home counties. London: Chief Medical Officers, 2011.

14. Physical Activity Guidelines Advisory Committee. Physical activity guidelines for Americans. Washington DC: US Department of Health and Human Services, 2008.

15. Canadian Society for Exercise Physiology. Canadian Physical Activity, and Sedentary Behaviour Guidelines. Secondary Canadian physical activity, and sedentary behaviour guidelines. 2012. http:// www.csep.ca/guidelines

16. Australian Government Department of Health and Ageing. Physical activity recommendations for 5-12 year olds. Canberra, Australia: Department of Health and Ageing, 2004.

17. American Academy of Pediatrics Committee on Public Education. Children, adolescents, and television. Pediatrics 2001;107:423-6.

18. Ekelund U, Luan JA, Sherar LB, et al. Moderate to vigorous physical activity and sedentary time and cardiometabolic risk factors in children and adolescents. JAMA 2012;307:704-12.

19. Kwon S, Burns TL, Levy SM, et al. Which contributes more to childhood adiposity-high levels of sedentarism or low levels of moderate-through-vigorous physical activity? The lowa bone development study. J Pediatr 2013;162:1169-74.

20. Mitchell JA, Mattocks C, Ness AR, et al. Sedentary behavior and obesity in a large cohort of children. Obesity 2009;17:1596-602.

21. Ghavamzadeh SA, Khalkhali HRB, Alizadeh MA. TV viewing independent of physical activity and obesogenic foods, increases overweight and obesity in adolescents. J Health Pop Nutr 2013;31:334-42.

22. Fulton JE, Wang X, Yore MM, et al. Television viewing, compute use, and BMI among US children and adolescents. J Phys Act Health 2009;6(Suppl 1):S28-35.

23. Stamatakis E, Coombs N, Jago R, et al. Associations between indicators of screen time and adiposity indices in Portuguese children. Prev Med 2013;56:299-303.

24. Joint Health Surveys Unit. The health survey for England 2008. Chapter 6: accelerometry in children. Leeds: The Information Centre for Health and Social Care, 2010.

25. Matthews CS, Chen KY, Freedson PS, et al. Amount of time spent in sedentary behaviors in the United States, 2003-2004. Am J Epidemiol 2008;167:875-81.

26. Craig R, Mindell J, Hirani V. Health survey for England 2008. Volume 1 physical activity and fitness. The Health and Social Care Information Centre, 2009.

27. Phillips AC, Holland AJ. Assessment of objectively measured physical activity levels in individuals with intellectual disabilities with and without Down's syndrome. PLoS ONE 2011;6:e28618.

28. Pietrobelli A, Faith MS, Allison DB, et al. Body mass index as a measure of adiposity in children and adolescents: a validation study. J Pediatr 1998;132:204-10.

29. Vidmar S, Carlin J, Hesketh K. Standardizing anthropometric measures in children and adolescents with new functions for egen. Stata J 2004;4:50-5.

30. Byun W, Liu J, Pate RR. Association between objectively measured sedentary behavior and body mass index in preschool children. Int $J$ Obes (Lond) 2013;37:961-5.

31. Pearson N, Biddle SJH. Sedentary behavior and dietary intake in children, adolescents, and adults: a systematic review. Am J Prev Med 2011;41:178-88. 
32. Manios $\mathrm{Y}$, Kourlaba G, Kondaki K, et al. Obesity and television watching in preschoolers in Greece: the GENESIS study. Obesity 2009;17:2047-53.

33. Marsh S, Ni Mhurchu C, Maddison R. The non-advertising effects of screen-based sedentary activities on acute eating behaviours in children, adolescents, and young adults. A systematic review. Appetite 2013;71:259-73.

34. Olafsdottir S, Berg C, Eiben G, et al. Young children's screen activities, sweet drink consumption and anthropometry: results from a prospective European study. Eur J Clin Nutr 2014;68:223-8.

35. Hastings G, McDermott L, Angus K, et al. The extent, nature and effects of food promotion to children: a review of the evidence.
Prepared for the World Health Organization. Geneva: Institute for Social Marketing, University of Stirling \& The Open University, United Kingdom, 2006.

36. Goris JM, Peterson S, Stamatakie E, et al. Television food advertising and the prevalence of childhood overweight and obesity: a multicountry comparison. Public Health Nutr 2009;13:1003-12.

37. Rey-López JP, Vicente-Rodríguez G, Biosca M, et al. Sedentary behaviour and obesity development in children and adolescents. Nutr Metab Cardiovasc Dis 2008;18:242-51.

38. Yates T, Wilmot EG, Khunti K, et al. Stand up for your health: is it time to rethink the physical activity paradigm? Diabetes Res Clin Pract 2011;93:292-4. 